\title{
Foxp3 Instability Helps tTregs Distinguish Self and Non-self
}

\begin{abstract}
Zhongmei Zhang ${ }^{1}$ and Xuyu Zhou ${ }^{2,3 *}$
${ }^{1}$ Experimental Immunology Branch, National Cancer Institute, National Institutes of Health, Bethesda, MD, United States, ${ }^{2}$ CAS Key Laboratory of Pathogenic Microbiology and Immunology, Institute of Microbiology, Chinese Academy of Sciences (CAS), Beijing, China, ${ }^{3}$ Savaid Medical School, University of Chinese Academy of Sciences, Beijing, China
\end{abstract}

Regulatory T cells (Tregs) are small subsets of CD4T cells that play a central role in the controlling of immune tolerance. Tregs are either generated in the thymus (tTregs) or the periphery (pTregs), and both express the master transcription factor Foxp3. Stable expression of Foxp3 is important for the maintenance of Tregs identity and their suppressive function. Similar to conventional T cells, Tregs can recognize both self- and non-self-antigens, and TCR engagement leads to Treg activation and the generation of effector Tregs. Emerging shreds of evidence suggest Tregs are not always stable, even fully committed mature tTregs, and can lose foxp3 expression and programming to effector-like T cells. In this review, we summarize recent findings in Treg instability and the intrinsic and extrinsic mechanisms in controlling the Foxp3 expression. Finally, we propose a new hypothesis that Foxp3 instability might help tTregs distinguish between self and non-self-antigens.

Keywords: Treg, Foxp3, instability, self and non-self-discrimination, TCR

Margarita Dominguez-Villar,

Imperial College London,

United Kingdom

Reviewed by:

Bruce Milne Hall,

University of New South

Wales, Australia

Xue-Zhong Yu,

Medical University of South Carolina,

United States

*Correspondence:

Xuyu Zhou

zhouxy@im.ac.cn

Specialty section: This article was submitted to

T Cell Biology,

a section of the journal

Frontiers in Immunology

Received: 15 July 2019 Accepted: 03 September 2019 Published: 24 September 2019

Citation:

Zhang $Z$ and Zhou X (2019) Foxp3 Instability Helps tTregs Distinguish Self

and Non-self.

Front. Immunol. 10:2226.

doi: 10.3389/fimmu.2019.02226

\section{INTRODUCTION}

$\mathrm{T}$ cells are one of the major components of the adaptive immune system which protects against all kind of pathogens, harmful substances, and foreign tissues. Immature $\mathrm{T}$ cells expressing an enormous number of TCRs generated by random VDJ recombination undergo selection in the thymus, where self-reactive $\mathrm{T}$ cells are clonally deleted through negative selection. However, this mechanism of controlling self-reactive T cells, known as central tolerance, is not perfect. Some potentially autoreactive $\mathrm{T}$ cells escape deletion in the thymus and migrate to the periphery. In recent years, we have learned that suppression of autoreactive lymphocytes relies on a subset of $\mathrm{T}$ lymphocytes called regulatory $\mathrm{T}$ cells, a small subpopulation of $\mathrm{CD} 4^{+} \mathrm{T}$ cells characterized by expression of the forkhead transcription factor Foxp3 (1).

Nishizuka and Sakakura were the first to show that thymus-derived Tregs mediate dominant self-tolerance (2). Their study showed that neonatal thymectomy around day 3 after birth resulted in severe autoimmune diseases, which could be prevented by adoptive transfer of thymocytes or splenocytes from adult euthymic mice (2). These observations demonstrated that a $\mathrm{T}$ cell subset generated in the mouse thymus after the third day of life could prevent autoimmunity. This $\mathrm{T}$ cell subset was later identified as a thymus-derived $\mathrm{CD} 25^{+} \mathrm{CD} 4^{+} \mathrm{T}$ cell population capable of protecting animals from autoimmune diseases $(3,4)$. However, CD25 is an activation marker, and by itself, is insufficient for identifying tolerance- and inflammation-promoting cells during an immune response. The breakthrough in the field came when the transcription factor Foxp3 was identified as the master regulator of Tregs (5-7). Expression of Foxp3 faithfully distinguishes naturally occurring thymic, as well as peripheral, $\mathrm{CD} 25^{+} \mathrm{CD} 4^{+}$Tregs from naive $\mathrm{CD} 25^{-} \mathrm{CD} 4^{+} \mathrm{T}$ cells or activated $\mathrm{CD} 4^{+} \mathrm{T}$ cells. Moreover, sustained Foxp3 expression in mature Tregs is critical for maintaining of the Treg cell identity and suppression of life-threatening autoimmunity (8). 
Although Tregs are likely to represent a stable cell lineage with regulatory functions, accumulating evidence suggests that Foxp $3^{+}$Tregs retain plasticity and can be "reprogrammed" into $\mathrm{T}$ helper cells under certain environmental conditions (9-12). In this review, we summarize recent results on Treg instability and discuss their implications in distinguishing self and non-self.

\section{MECHANISMS OF FOXP3 INDUCTION AND MAINTENANCE}

The induction and maintenance of Foxp3 distinguish Tregs from the other $\mathrm{T}$ helper cell populations. Interestingly, these two processes are largely separable and regulated by Foxp3 promoter and three conserved non-coding sequences (CNS) located around the first intron and the first coding exon of the Foxp3 gene (13-15). Intrathymic differentiation of Tregs is synchronized with positive and/or negative selection and starts mostly at the $\mathrm{CD} 4^{+} \mathrm{CD} 8^{-}$single-positive (CD4SP) stage $(16,17)$. By using TCR and antigen double transgenic systems, it was shown that $\mathrm{CD} 25^{+} \mathrm{CD} 4^{+}$cells can differentiate into Tregs in the thymus when the cognate antigen is presented by thymic stromal cells $(18,19)$. These results suggest that Treg cells develop from CD4 SP T cells possessing TCRs with high avidity toward self-antigens $(20,21)$. Thymic Foxp3 induction and Treg lineage commitment are the synergistic effects of TCR signaling, costimulatory signals through CD28 and common $\gamma$-chain cytokine signals, particularly IL-2 signal (22-26). Transcription factors such as NFAT, AP-1, Nr4a factors, and STAT- 5 can drive Foxp3 promoter activation in response to TCR and IL-2 signaling (2729). Tregs can also be induced in the periphery from naïve conventional $\mathrm{CD} 4^{+} \mathrm{T}$ cells, and these pTregs play an important role in maintaining intestinal mucosal immune tolerance and maternal-fetal tolerance (30-32). Interestingly, $p$ Tregs and tTregs have different dependence on CNS-1, which contains a TGF$\beta$-NFAT response element, and is indispensable for peripheral, but not thymic, Foxp3 induction $(15,33)$. Additionally, CNS3, another cis-element regulating Foxp3 locus, acts as a pioneering element essential for inducing of Foxp3 expression (13). CNS3 recruits c-Rel and Foxo family transcription factors such as Foxo1 and Foxo3, which can open the Foxp3 gene locus, thereby facilitating Foxp3 induction $(34,35)$.

Stable expression of Foxp3 is dependent on CNS2, a CpGrich region within Foxp3 locus. CNS2, also called Treg specific demethylation region (TSDR), is dispensable for Foxp3 induction but essential for heritable maintenance of Foxp3 expression in dividing Tregs $(13,14)$. CNS2 is fully methylated in conventional $\mathrm{T}$ cells (Tconvs) and highly methylated in Tregs generated recently in the thymus. Demethylation of CNS2 contributes to stable Foxp3 expression in Tregs $(36,37)$. The initiation of TSDR demethylation is Foxp3-independent, as the "wannabe" Tregs, which transcribe the Foxp3 locus but do not express Foxp3 protein, show demethylation of the $\operatorname{TSDR}(13,36)$. Recent studies have revealed the roles of Ten-eleven translocation (TET) proteins, which can induce the demethylation of 5methylcytosine $(5 \mathrm{mC})$ in a cell cycle-independent way, in the demethylation of CNS2 (38). By using CD4-Cre and Foxp3Cre-mediated depletion of Tet2/Tet3, Rao et al. and Yoshimura et al. showed that the Tet proteins play a critical role in demethylating TSDR to ensure stable Foxp3 transcription (39, 40). Once the TSDR has been demethylated, Foxp3 protein, cooperating with other transcription factors such as Runx/Cbf $\beta$, STAT5, CREB/ATF, and Ets-1, binds to the demethylated TSDR and stabilizes its own transcription through a positive feedback mechanism $(13,41-43)$. Rao et al. also observed that four CpGs in CNS1 and $11 \mathrm{CpGs}$ in CNS2 share a similar CpG methylation pattern (38). Collectively, these findings show that the establishment of stable expression of Foxp3 occurs in a two-step process, the first step being the Tet- dependent demethylation of TSDR, followed by Foxp3-dependent selfenforcement. Moreover, the metabolic status during tTreg cell activation and environmental cytokine cues also contribute to the stability of Foxp3 expression (44-49).

\section{EVIDENCE OF INSTABILITY OF FOXP3}

Accumulating evidence suggests that Foxp $3^{+}$cells are not terminally differentiated. Indeed, in vitro culture system and in vivo transfer experiments showed that a fraction of Tregs can lose their Foxp3 expression and acquire the ability to produce the corresponding Th cytokines depending on their microenvironment $(10,50,51)$. To overcome the limitations of the relatively artificial experimental setting used in these experiments and directly address the problem in vivo, we have used genetic lineage-tracing approaches. To identify exFoxp3 T cells in the normal $\mathrm{T}$ cell repertoire, we generated a fatemapping system by crossing ROSA26 YFP-reporter mice with Foxp3 bacterial artificial chromosome (BAC) transgenic mice expressing a GFP-Cre fusion protein (9). We found that 10$15 \%$ of $\mathrm{YFP}^{+}$cells did not express Foxp3 and GFP, and these $\mathrm{GFP}^{-} \mathrm{YFP}^{+}$cells displayed an activated memory $\mathrm{T}$ cell phenotype with the ability to produce pro-inflammatory cytokines, IFN- $\gamma$ and IL-17. Moreover, when crossed with transgenic mice expressing a diabetogenic TCR, the frequency of exFoxp3 cells increased in the inflamed pancreas and these cells conferred autoimmune diabetes upon adoptive transfer into lymphopenic mice. Similar results were observed by using MOG tetramer to identify antigen-specific Tregs in an experimental autoimmune encephalomyelitis (EAE) model, further supporting the notion that Tregs can be converted into pathogenic T helper cells in vivo (11). Collectively, these observations suggest that Foxp $^{+}$Tregs can lose Foxp3 expression and undergo lineage reprogramming in response to certain extrinsic cues such as lymphopenia and inflammation.

\section{CONTRADICTION AND POSSIBLE EXPLANATIONS}

Conclusions drawn from these studies have generated great debates. Treg plays a critical role in maintaining self-tolerance and many Tregs are biased toward self-recognition. In this context, unlimited functional reprogramming of Tregs to pathogenic effector $\mathrm{T}$ cells could have a disastrous effect on the host. The reprogramming model has been challenged by 
a study from Rudensky et al., who utilized an induciblelabeling approach by knocking in a cDNA encoding GFP-CreERT2 fusion protein into a $3^{\prime}$ untranslated region (UTR) of the Foxp3 gene, and then crossing these mice with ROSA26 YFP mice (52). When treated with tamoxifen to pulse label Foxp $^{+} \mathrm{T}$ cells, Rudensky et al. found that $<5 \%$ of $\mathrm{YFP}^{+}$cells were Foxp3 negative. The frequency of Foxp $3^{-}$cells did not increase even under inflammatory or lymphopenic conditions, suggesting that Foxp3 expression in Tregs was remarkably stable. The contradiction is unlikely to be due to an unfaithful reflection of endogenous Foxp3 expression by Foxp3-GFP-Cre BAC construct, as an independent Foxp3 GFP-Cre knock-in $\mathrm{x}$ ROSA26 RFP fate mapping system also showed that about $15 \%$ of peripheral Foxp3 traced $\mathrm{RFP}^{+} \mathrm{T}$ cells were indeed Foxp $3^{-}$(53). Interestingly, different subsets of Tregs might have different Foxp3 stability, which even changes according to their developmental stages $(33,36,37,54)$. It is well-known that in vitro iTregs, induced by TGF- $\beta$, have highly methylated TSDR and are prone to lose Foxp3 (37). Rudensky et al. have shown that newly generated pTregs were unstable, about $50 \%$ of lineage-traced cells were Foxp $3^{-}$, whereas stable pTregs were generated only after 5 weeks upon transferring (33). The labeling efficiency of Tregs during fate mapping experiment, particularly the unstable pTregs, could be a potential factor for the inconsistent results among different models.

To resolve the controversies regarding the stability of Foxp3, Hori have proposed a heterogeneity model and postulated that exFoxp3s do not indicate real reprogramming of Tregs but reflect a minor population of uncommitted Foxp3 ${ }^{+} \mathrm{T}$ cells which have lost their Foxp3 expression (55). According to this heterogeneity model, uncommitted Tregs are a minor fraction of the Foxp $3^{+} \mathrm{CD} 25^{-}$subset, generated either from transient Foxp3 expression during the activation of peripheral $\mathrm{T}$ cells, or from immature tTregs that fail to demethylate CNS2 during thymic Treg development, thereby becoming susceptible to losing Foxp3 expression in lymphopenic and in vitro polarization settings (50). In contrast, most, if not all, of the $\mathrm{CD} 25^{+}$ Foxp $^{+} \mathrm{T}$ cells show stable Foxp3 expression under those conditions. Although the heterogeneity model is compatible with the two fate-mapping experiments mentioned before, it fails to shed any light on whether the fully committed tTregs can lose Foxp3 expression. Moreover, CD25 expression was significantly decreased following Treg activation and functional specialization (T-bet ${ }^{+}$Treg, Bcl6 ${ }^{+}$TFR, etc.) $(12,56)$, and effector Tregs preferentially use ICOS instead of IL-2 signaling to support homeostasis and function (57). If so, can activated/effector Tregs maintain Foxp3 expression?

\section{TCR SIGNAL DETERMINES THE INSTABILITY OF TREG}

The heterogeneity and reprogramming models are not mutually exclusive. Recently, we have generated a new fate-mapping system which traces only the epigenetically stable tTregs, and that provides us a unique opportunity to address the above questions mentioned before (12). It has been demonstrated that the CNS1, which serves as a major TGF- $\beta$ sensor, is critical for the generation of induced pTregs, but largely dispensable for tTreg development (33). Based on this observation, we developed a delta CNS1 Foxp3 BAC transgene mouse strain in which only

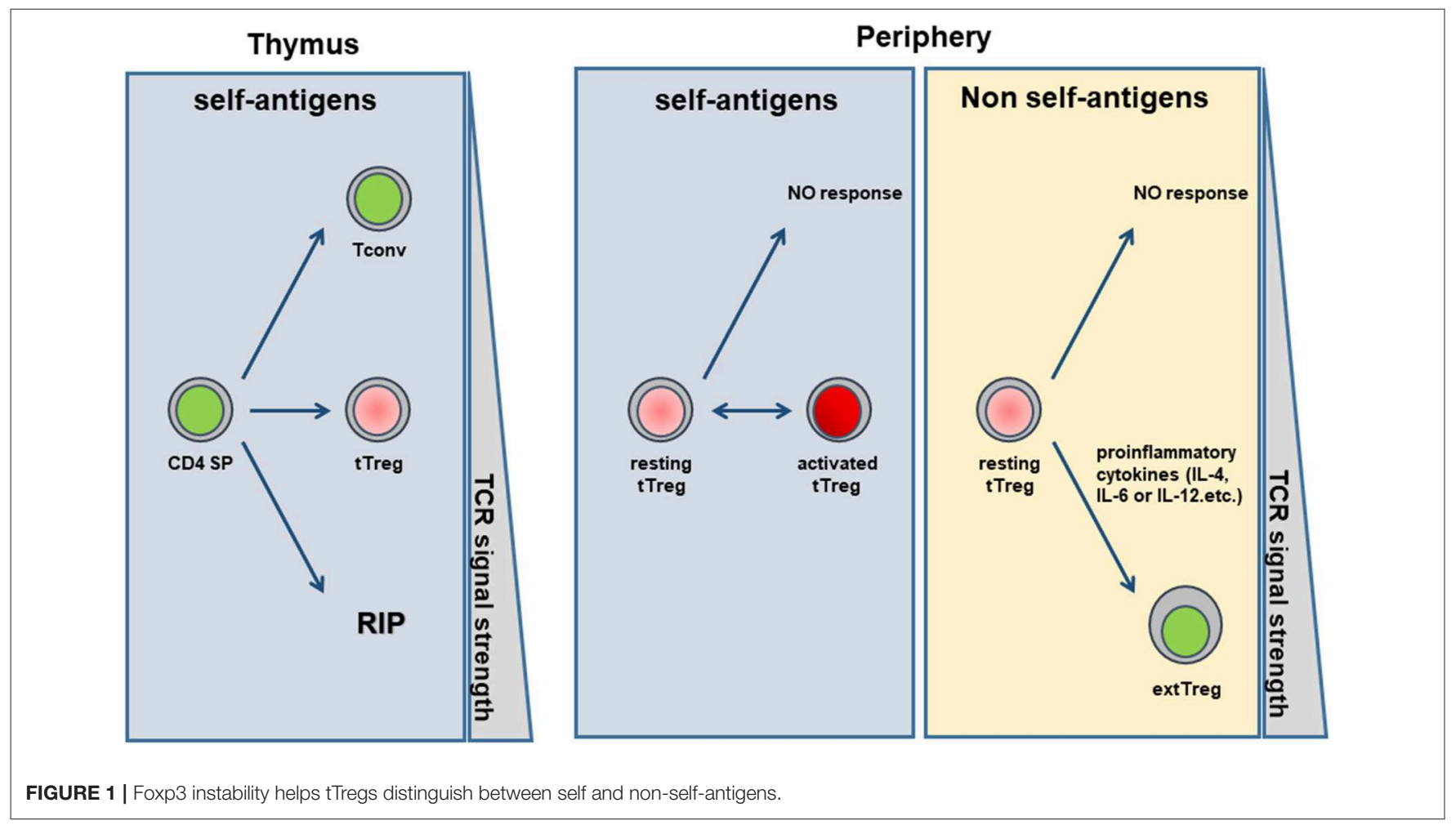


tTregs express the Thy1.1-Cre fusion protein (referred to as Foxp3 delta CNS1-Cre-Thy1.1). Unexpectedly, the expression of Thy1.1-Cre reporter was significantly delayed in the thymus and marked the mature tTregs with hypomethylation of the TSDR. By using the Foxp3 delta CNS1-Cre-Thy1.1 x ROSA26 YFP fate-mapping system, we studied the stability of bona fide tTregs. We found that only $\sim 1 \%$ of mature tTregs lost Foxp3 expression in secondary lymphoid organs, indicating that tTregs are stable under homeostatic conditions. However, activation and sequential functional specialization of tTregs (conversion to $\mathrm{T}$ bet $^{+}$Treg and Bcl6 ${ }^{+}$TFR) result in the loss of Foxp3 stability and reprogramming into $\mathrm{T}$ helper lineage. Destabilization of Foxp3 can also happen in Th2-like Treg or Th17-like Treg. Chatila et al. have shown that selective boosting of IL-4R signaling by introducing a gain-of-function IL-4R $\alpha$ (Il4raF709) in Tregs can reprogram Treg to Th2 cells (58). Similarly, augmentation of Ror $\gamma \mathrm{t}$ by knocking-out both T-bet and GATA3 in Tregs results in decreasing Foxp3 expression and generation of IL-17 producing cells (59). We further demonstrated that the signal switch from IL-2 to ICOS/PI3K during Treg activation account for Foxp3 instability and Treg reprogramming (12). Initiation of TSDR remethylation is likely the key step for loss of Foxp3 expression (9), death of activated Treg, and survival and expansion of $\mathrm{T}$ helper cells could further drive the conversion.

To trace the functional specification of Tregs in vivo, we have used a dual lineage tracing mouse model in which the genetic tracing of Foxp3 and T-bet was simultaneously enabled (12). Interestingly, "exT-bet" Foxp $3^{+}$cells (T-bet-tracer positive Tregs that had lost T-bet expression) reverted to restinglike Treg phenotypes with stable Foxp3 expression, whereas sustained T-bet expressing effector Tregs tend to lose Foxp3 expression. Together, these results suggest that over-stimulation likely promotes the instability of Tregs and converts them from immune-suppressing cells to immune-boosting cells.

\section{FOXP3 INSTABILITY MAY HELP TTREGS DISTINGUISH SELF AND NON-SELF}

Considering all these observations, we propose the hypothesis that Foxp3 instability may help tTregs distinguish between self and non-self-antigens (Figure 1). Both conventional T cells and tTreg develop in the thymus, possibly from the same pool of diversified immature $\mathrm{T}$ cells. Thymocytes are educated by an elaborate process, during which their fate was determined by the affinity of the TCRs for self-peptide-MHC complexes on APCs. CD4 SP cells that bind with high affinity to self-antigens undergo clonal deletion to limit autoimmunity, whereas the thymocytes that bind with low affinity against the self-ligands can survive and emigrate to the periphery as conventional $\mathrm{T}$ cells. Tregs are positively selected from the TCRs with the affinity between the clonally deleted autoreactive $\mathrm{T}$ cells and Tconvs. In the periphery, Tconvs usually remain inactive due to their low affinity to self-ligands. When the organism is infected by pathogens, Tconvs, having high affinity against foreign antigens, undergo clonal expansion to differentiate into effector cells and protect the host. Similar to T conventional cells, TCR engagement is also a critical step for Treg activation and gain of potent suppressive function $(60,61)$. Although tTregs are selected by self-antigens in the thymus, many studies have suggested that a substantial proportion of thymic Tregs recognize foreign antigens. Because TCRs on Tregs has an intermediate affinity to self-ligands, most of the self-ligands in the periphery can only activate tTregs to a certain extent, thereby maintaining a perfect window in which Treg activation is triggered but their stability is not impaired. In contrast to self-antigens, foreign antigens could trigger strong TCR signals due to lack of negative selection, and the strong signal could induce a high level of ICOS/PI3K activation that is detrimental to Treg suppressive activity and stability (12, 45, 62). In addition to TCR signaling, proinflammatory cytokines induced by infection such as IL-6, IL-12, or IL- 4 can also have a disruptive effect on Treg stability $(50,51,63)$. Thus, those Tregs, which respond vigorously are prone to losing their suppressive function, program into an immune-boosting cell, and contribute to clearance of pathogens. Indeed, loss of Treg stability has been observed in many pathologic conditions in response to foreign antigens such as infection and allergy (64-66). This hypothesis would explain many general phenomena in which Tregs can control weak immune responses, while being relatively incompetent to suppress strong immune responses, such as alloskin grafts. Consistent with this notion, Amigorena et al. have demonstrated that Tregs could down-regulate low-avidity CD8 reactions but promote the high-avidity of $\mathrm{CD} 8^{+} \mathrm{T}$ cell responses to foreign antigen (67).

\section{CONCLUSIONS}

Although many controversies remain, more and more pieces of evidence have supported the notion that Tregs can lose Foxp3 expression under certain conditions. In the past 10 years, the extracellular and intracellular signals that maintain or destabilize Foxp3 have been intensively investigated, however, the physiologic function of Treg instability is not fully understood. We propose a hypothesis that Foxp3 instability helps tTreg to distinguish self and non-self-antigens. A better understanding of this question might have important therapeutic applications in a variety of diseases ranging from tumor to infectious disease.

\section{AUTHOR CONTRIBUTIONS}

$\mathrm{ZZ}$ and $\mathrm{XZ}$ wrote the manuscript.

\section{FUNDING}

This work was supported by the National Science and Technology Major Project of China (No. 2018ZX10301-208-002002 and 2016ZX10004222-007).

\section{ACKNOWLEDGMENTS}

We thank Dr. Xuguang Tai and Dr. Abhisek Bhattacharya for critical review of the manuscript and gratefully acknowledge Prof. Alfred Singer for discussions. 


\section{REFERENCES}

1. Sakaguchi S. Naturally arising $\mathrm{CD} 4^{+}$regulatory $\mathrm{T}$ cells for immunologic selftolerance and negative control of immune responses. Ann Rev Immunol. (2004) 22:531-62. doi: 10.1146/annurev.immunol.21.120601.141122

2. Nishizuka Y, Sakakura T. Thymus and reproduction: sex-linked dysgenesia of the gonad after neonatal thymectomy in mice. Science. (1969) 166:753-5. doi: $10.1126 /$ science. 166.3906 .753

3. Itoh M, Takahashi T, Sakaguchi N, Kuniyasu Y, Shimizu J, Otsuka F, et al. Thymus and autoimmunity: production of $\mathrm{CD} 25^{+} \mathrm{CD} 4^{+}$naturally anergic and suppressive $\mathrm{T}$ cells as a key function of the thymus in maintaining immunologic self-tolerance. J Immunol. (1999) 162:5317-26.

4. Sakaguchi S, Sakaguchi N, Asano M, Itoh M, Toda M. Immunologic selftolerance maintained by activated $\mathrm{T}$ cells expressing IL-2 receptor alphachains (CD25). Breakdown of a single mechanism of self-tolerance causes various autoimmune diseases. J Immunol. (1995) 155:1151-64.

5. Hori S, Nomura T, Sakaguchi S. Control of regulatory T cell development by the transcription factor Foxp3. Science. (2003) 299:1057-61. doi: 10.1126/science. 1079490

6. Fontenot JD, Gavin MA, Rudensky AY. Foxp3 programs the development and function of $\mathrm{CD}^{+}{ }^{+} \mathrm{CD} 25^{+}$regulatory T cells. Nat Immunol. (2003) 4:330-6. doi: $10.1038 /$ ni904

7. Khattri R, Cox T, Yasayko S-A, Ramsdell F. An essential role for Scurfin in $\mathrm{CD} 4{ }^{+} \mathrm{CD} 25^{+}$T regulatory cells. Nat Immunol. (2003) 4:337-42. doi: $10.1038 /$ ni909

8. Williams LM, Rudensky AY. Maintenance of the Foxp3-dependent developmental program in mature regulatory $\mathrm{T}$ cells requires continued expression of Foxp3. Nat Immunol. (2007) 8:277. doi: 10.1038/ni1437

9. Zhou X, Bailey-Bucktrout SL, Jeker LT, Penaranda C, Martínez-Llordella $\mathrm{M}$, Ashby $\mathrm{M}$, et al. Instability of the transcription factor Foxp3 leads to the generation of pathogenic memory T cells in vivo. Nat Immunol. (2009) 10:1000. doi: 10.1038/ni.1774

10. Tsuji M, Komatsu N, Kawamoto S, Suzuki K, Kanagawa O, Honjo T, et al. Preferential generation of follicular B helper T cells from Foxp $3^{+} \mathrm{T}$ Cells in gut Peyer's patches. Science. (2009) 323:1488-92. doi: 10.1126/science.1169152

11. Bailey-Bucktrout Samantha L, Martinez-Llordella M, Zhou X, Anthony B, Rosenthal W, Luche $\mathrm{H}$, et al. Self-antigen-driven activation induces instability of regulatory $\mathrm{T}$ cells during an inflammatory autoimmune response. Immunity. (2013) 39:949-62. doi: 10.1016/j.immuni.2013. 10.016

12. Zhang Z, Zhang W, Guo J, Gu Q, Zhu X, Zhou X. Activation and functional specialization of regulatory $\mathrm{T}$ cells lead to the generation of Foxp3 instability. J Immunol. (2017) 198:2612-25. doi: 10.4049/jimmunol.1601409

13. Zheng Y, Josefowicz S, Chaudhry A, Peng XP, Forbush K, Rudensky AY. Role of conserved non-coding DNA elements in the Foxp3 gene in regulatory T-cell fate. Nature. (2010) 463:808. doi: 10.1038/nature08750

14. Li X, Liang Y, LeBlanc M, Benner C, Zheng Y. Function of a Foxp3 cisElement in protecting regulatory $\mathrm{T}$ cell identity. Cell. (2014) 158:734-48. doi: 10.1016/j.cell.2014.07.030

15. Tone Y, Furuuchi K, Kojima Y, Tykocinski ML, Greene MI, Tone M. Smad3 and NFAT cooperate to induce Foxp3 expression through its enhancer. Nat Immunol. (2007) 9:194. doi: 10.1038/ni1549

16. Fontenot JD, Rasmussen JP, Williams LM, Dooley JL, Farr AG, Rudensky AY. Regulatory T cell lineage specification by the forkhead transcription factor Foxp3. Immunity. (2005) 22:329-41. doi: 10.1016/j.immuni.2005. 01.016

17. Fontenot JD, Dooley JL, Farr AG, Rudensky AY. Developmental regulation of Foxp3 expression during ontogeny. J Exp Med. (2005) 202:901-6. doi: $10.1084 /$ jem.20050784

18. Apostolou I, Sarukhan A, Klein L, von Boehmer H. Origin of regulatory T cells with known specificity for antigen. Nat Immunol. (2002) 3:756-63. doi: 10.1038/ni816

19. Jordan MS, Boesteanu A, Reed AJ, Petrone AL, Holenbeck AE, Lerman MA, et al. Thymic selection of $\mathrm{CD}^{+} \mathrm{CD}^{+}$regulatory $\mathrm{T}$ cells induced by an agonist self-peptide. Nat Immunol. (2001) 2:301-6. doi: 10.1038/86302

20. Hsieh C-S, Liang Y, Tyznik AJ, Self SG, Liggitt D, Rudensky AY. Recognition of the peripheral self by naturally arising $\mathrm{CD} 25^{+} \mathrm{CD} 4^{+} \mathrm{T}$ cell receptors. Immunity. (2004) 21:267-77. doi: 10.1016/j.immuni.2004.07.009
21. Pacholczyk R, Kern J, Singh N, Iwashima M, Kraj P, Ignatowicz L. Nonselfantigens are the cognate specificities of Foxp $3^{+}$regulatory T cells. Immunity. (2007) 27:493-504. doi: 10.1016/j.immuni.2007.07.019

22. Tai X, Cowan M, Feigenbaum L, Singer A. CD28 costimulation of developing thymocytes induces Foxp3 expression and regulatory $\mathrm{T}$ cell differentiation independently of interleukin 2. Nat Immunol. (2005) 6:152-62. doi: $10.1038 /$ ni1 160

23. Fontenot JD, Rasmussen JP, Gavin MA, Rudensky AY. A function for interleukin 2 in Foxp3-expressing regulatory T cells. Nat Immunol. (2005) 6:1142-51. doi: 10.1038/ni1263

24. Burchill MA, Yang J, Vogtenhuber C, Blazar BR, Farrar MA. IL-2 receptor $\beta$-dependent STAT5 activation is required for the development of Foxp $^{+}$regulatory $\mathrm{T}$ cells. J Immunol. (2007) 178:280-90. doi: 10.4049/jimmunol.178.1.280

25. Yao Z, Kanno Y, Kerenyi M, Stephens G, Durant L, Watford WT, et al. Nonredundant roles for Stat5a/b in directly regulating Foxp3. Blood. (2007) 109:4368-75. doi: 10.1182/blood-2006-11-055756

26. Burchill MA, Yang J, Vang KB, Moon JJ, Chu HH, Lio C-WJ, et al. Linked $\mathrm{T}$ cell receptor and cytokine signaling govern the development of the regulatory $\mathrm{T}$ cell repertoire. Immunity. (2008) 28:112-21. doi: 10.1016/j.immuni.2007.11.022

27. Sekiya T, Kashiwagi I, Yoshida R, Fukaya T, Morita R, Kimura A, et al. Nr4a receptors are essential for thymic regulatory $\mathrm{T}$ cell development and immune homeostasis. Nat Immunol. (2013) 14:230. doi: 10.1038/ni.2520

28. Long M, Park S-G, Strickland I, Hayden MS, Ghosh S. Nuclear factor- $\kappa B$ modulates regulatory $\mathrm{T}$ cell development by directly regulating expression of Foxp3 transcription factor. Immunity. (2009) 31:921-31. https://doi.org/10. 1016/j.immuni.2009.09.022

29. Zorn E, Nelson EA, Mohseni M, Porcheray F, Kim H, Litsa D, et al. IL2 regulates FOXP3 expression in human $\mathrm{CD} 4^{+} \mathrm{CD} 25^{+}$regulatory $\mathrm{T}$ cells through a STAT-dependent mechanism and induces the expansion of these cells in vivo. Blood. (2006) 108:1571-9. doi: 10.1182/blood-2006-02-004747

30. Mucida D, Kutchukhidze N, Erazo A, Russo M, Lafaille JJ, Curotto de Lafaille MA. Oral tolerance in the absence of naturally occurring Tregs. J Clin Invest. (2005) 115:1923-33. doi: 10.1172/JCI24487

31. Atarashi K, Tanoue T, Shima T, Imaoka A, Kuwahara T, Momose Y, et al. Induction of colonic regulatory $\mathrm{T}$ cells by indigenous Clostridium Species. Science. (2011) 331:337-41. doi: 10.1126/science.1198469

32. Samstein Robert M, Josefowicz Steven Z, Arvey A, Treuting Piper M, Rudensky Alexander Y. Extrathymic generation of regulatory $\mathrm{T}$ cells in placental mammals mitigates maternal-fetal conflict. Cell. (2012) 150:29-38. doi: 10.1016/j.cell.2012.05.031

33. Josefowicz SZ, Niec RE, Kim HY, Treuting P, Chinen T, Zheng Y, et al. Extrathymically generated regulatory $\mathrm{T}$ cells control mucosal TH2 inflammation. Nature. (2012) 482:395. doi: 10.1038/nature10772

34. Ruan Q, Kameswaran V, Tone Y, Li L, Liou H-C, Greene $\mathrm{MI}$, et al. Development of $\mathrm{Foxp}^{+}$regulatory $\mathrm{T}$ cells is driven by the c-Rel enhanceosome. Immunity. (2009) 31:932-40. doi: 10.1016/j.immuni.2009.10.006

35. Ouyang W, Beckett O, Ma Q, Paik J-h, DePinho RA, Li MO. Foxo proteins cooperatively control the differentiation of Foxp $3^{+}$regulatory T cells. Nat Immunol. (2010) 11:618. doi: 10.1038/ni.1884

36. Ohkura N, Hamaguchi M, Morikawa H, Sugimura K, Tanaka A, Ito $\mathrm{Y}$, et al. $\mathrm{T}$ cell receptor stimulation-induced epigenetic changes and Foxp3 expression are independent and complementary events required for treg cell development. Immunity. (2012) 37:785-99. doi: 10.1016/j.immuni.2012.09.010

37. Floess S, Freyer J, Siewert C, Baron U, Olek S, Polansky J, et al. Epigenetic control of the Foxp3 locus in regulatory T cells. PLoS Biol. (2007) 5:e38. doi: 10.1371/journal.pbio.0050038

38. Yue X, Trifari S, Äijö T, Tsagaratou A, Pastor WA, Zepeda-Martínez JA, et al. Control of Foxp3 stability through modulation of TET activity. J Exp Med. (2016) 213:377-97. doi: 10.1084/jem.20151438

39. Yue X, Lio C-WJ, Samaniego-Castruita D, Li X, Rao A. Loss of TET2 and TET3 in regulatory T cells unleashes effector function. Nat Commun. (2019) 10:2011. doi: 10.1038/s41467-019-09541-y

40. Nakatsukasa H, Oda M, Yin J, Chikuma S, Ito M, Koga-Iizuka M, et al. Loss of TET proteins in regulatory $\mathrm{T}$ cells promotes abnormal proliferation, 
Foxp3 destabilization and IL-17 expression. Int Immunol. (2019) 31:335-47. doi: 10.1093/intimm/dxz008

41. Polansky JK, Schreiber L, Thelemann C, Ludwig L, Krüger M, Baumgrass R, et al. Methylation matters: binding of Ets-1 to the demethylated Foxp3 gene contributes to the stabilization of Foxp3 expression in regulatory T cells. J Mol Med. (2010) 88:1029-40. doi: 10.1007/s00109-010-0642-1

42. Kim H-P, Leonard WJ. CREB/ATF-dependent T cell receptor-induced FoxP3 gene expression: a role for DNA methylation. J Exp Med. (2007) 204:1543-51. doi: 10.1084/jem.20070109

43. Rudra D, Egawa T, Chong MMW, Treuting P, Littman DR, Rudensky AY. Runx-CBF $\beta$ complexes control expression of the transcription factor Foxp3 in regulatory T cells. Nat Immunol. (2009) 10:1170. doi: 10.1038/ni.1795

44. Galgani M, De Rosa V, La Cava A, Matarese G. Role of metabolism in the immunobiology of regulatory T cells. J Immunol. (2016) 197:2567-75. doi: 10.4049 /jimmunol.1600242

45. Shrestha S, Yang K, Guy C, Vogel P, Neale G, Chi H. Treg cells require the phosphatase PTEN to restrain TH1 and TFH cell responses. Nat Immunol. (2015) 16:178. doi: 10.1038/ni.3076

46. Wei J, Long L, Yang K, Guy C, Shrestha S, Chen Z, et al. Autophagy enforces functional integrity of regulatory $\mathrm{T}$ cells by coupling environmental cues and metabolic homeostasis. Nat Immunol. (2016) 17:277. doi: 10.1038/ni.3365

47. Barbi J, Pardoll D, Pan F. Treg functional stability and its responsiveness to the microenvironment. Immunol Rev. (2014) 259:115-39. doi: 10.1111/imr. 12172

48. Hoeppli RE, Wu D, Cook L, Levings MK. The environment of regulatory T cell biology: cytokines, metabolites, and the microbiome. Front. Immunol. (2015) 6:61. doi: 10.3389/fimmu.2015.00061

49. Li J, Heinrichs J, Haarberg K, Semple K, Veerapathran A, Liu C, et al. HYspecific induced regulatory $\mathrm{T}$ cells display high specificity and efficacy in the prevention of acute graft-versus-host disease. J Immunol. (2015) 195:717-25. doi: 10.4049/jimmunol.1401250

50. Komatsu N, Mariotti-Ferrandiz ME, Wang Y, Malissen B, Waldmann H, Hori S. Heterogeneity of natural Foxp $3^{+} \mathrm{T}$ cells: a committed regulatory T-cell lineage and an uncommitted minor population retaining plasticity. Proc Natl Acad Sci USA. (2009) 106:1903-8. doi: 10.1073/pnas.08115 56106

51. Yang XO, Nurieva R, Martinez GJ, Kang HS, Chung Y, Pappu BP, et al. Molecular antagonism and plasticity of regulatory and inflammatory $\mathrm{T}$ cell programs. Immunity. (2008) 29:44-56. doi: 10.1016/j.immuni.2008.05.007

52. Rubtsov YP, Niec RE, Josefowicz S, Li L, Darce J, Mathis D, et al. Stability of the regulatory $\mathrm{T}$ cell lineage in vivo. Science. (2010) 329:1667-71. doi: 10.1126/science.1191996

53. Miyao T, Floess S, Setoguchi R, Luche H, Fehling Hans J, Waldmann H, et al. Plasticity of Foxp $3^{+} \mathrm{T}$ cells reflects promiscuous Foxp3 expression in conventional T cells but not reprogramming of regulatory T cells. Immunity. (2012) 36:262-75. doi: 10.1016/j.immuni.2011.12.012

54. Toker A, Engelbert D, Garg G, Polansky JK, Floess S, Miyao T, et al. Active demethylation of the Foxp3 locus leads to the generation of stable regulatory T cells within the thymus. J Immunol. (2013) 190:3180-8. doi: 10.4049/jimmunol.1203473

55. Hori S. Developmental plasticity of Foxp $3^{+}$regulatory T cells. Curr Opin Immunol. (2010) 22:575-82. doi: 10.1016/j.coi.2010.08.004
56. Wing JB, Kitagawa Y, Locci M, Hume H, Tay C, Morita T, et al. A distinct subpopulation of $\mathrm{CD}^{-} 5^{-}$T-follicular regulatory cells localizes in the germinal centers. Proc Natl Acad Sci USA. (2017) 114:E6400-9. doi: 10.1073/pnas.1705551114

57. Smigiel KS, Richards E, Srivastava S, Thomas KR, Dudda JC, Klonowski KD, et al. CCR7 provides localized access to IL-2 and defines homeostatically distinct regulatory $\mathrm{T}$ cell subsets. J Exp Med. (2014) 211:121-36. doi: 10.1084/jem.20131142

58. Noval Rivas M, Burton OT, Wise P, Charbonnier LM, Georgiev P, Oettgen $\mathrm{HC}$, et al. Regulatory $\mathrm{T}$ cell reprogramming toward a Th2-cell-like lineage impairs oral tolerance and promotes food allergy. Immunity. (2015) 42:51223. doi: 10.1016/j.immuni.2015.02.004

59. Yu F, Sharma S, Edwards J, Feigenbaum L, Zhu J. Dynamic expression of transcription factors T-bet and GATA-3 by regulatory T cells maintains immunotolerance. Nat Immunol. (2015) 16:197-206. doi: 10.1038/ni.3053

60. Levine AG, Arvey A, Jin W, Rudensky AY. Continuous requirement for the TCR in regulatory T cell function. Nat Immunol. (2014) 15:1070. doi: $10.1038 /$ ni.3004

61. Vahl JC, Drees C, Heger K, Heink S, Fischer Julius C, Nedjic J, et al. Continuous $\mathrm{T}$ cell receptor signals maintain a functional regulatory $\mathrm{T}$ cell pool. Immunity. (2014) 41:722-36. doi: 10.1016/j.immuni.2014.10.012

62. Huynh A, DuPage M, Priyadharshini B, Sage PT, Quiros J, Borges CM, et al. Control of PI(3) kinase in Treg cells maintains homeostasis and lineage stability. Nat Immunol. (2015) 16:188. doi: 10.1038/ni.3077

63. Gao Y, Tang J, Chen W, Li Q, Nie J, Lin F, et al. Inflammation negatively regulates FOXP3 and regulatory T-cell function via DBC1. Proc Natl Acad Sci USA. (2015) 112:E3246-54. doi: 10.1073/pnas.1421463112

64. Oldenhove G, Bouladoux N, Wohlfert EA, Hall JA, Chou D, Dos santos $\mathrm{L}$, et al. Decrease of Foxp3 ${ }^{+}$Treg cell number and acquisition of effector cell phenotype during lethal infection. Immunity. (2009) 31:772-86. doi: 10.1016/j.immuni.2009.10.001

65. Pelly VS, Coomes SM, Kannan Y, Gialitakis M, Entwistle LJ, Perez-Lloret J, et al. Interleukin 4 promotes the development of ex-Foxp3 Th2 cells during immunity to intestinal helminths. J Exp Med. (2017) 214:1809-26. doi: $10.1084 /$ jem.20161104

66. Bhela S, Varanasi SK, Jaggi U, Sloan SS, Rajasagi NK, Rouse BT. The plasticity and stability of regulatory $\mathrm{T}$ cells during viral-induced inflammatory lesions. $J$ Immunol. (2017) 199:1342-52. doi: 10.4049/jimmunol.1700520

67. Pace L, Tempez A, Arnold-Schrauf C, Lemaitre F, Bousso P, Fetler L, et al. Regulatory T cells increase the avidity of primary $\mathrm{CD} 8^{+} \mathrm{T}$ cell responses and promote memory. Science. (2012) 338:532-6. doi: 10.1126/science.1227049

Conflict of Interest Statement: The authors declare that the research was conducted in the absence of any commercial or financial relationships that could be construed as a potential conflict of interest.

Copyright (c) 2019 Zhang and Zhou. This is an open-access article distributed under the terms of the Creative Commons Attribution License (CC BY). The use, distribution or reproduction in other forums is permitted, provided the original author(s) and the copyright owner(s) are credited and that the original publication in this journal is cited, in accordance with accepted academic practice. No use, distribution or reproduction is permitted which does not comply with these terms. 